\title{
Involvement of heparanase in the pathogenesis of acute kidney injury: nephroprotective effect of PG545
}

\author{
Zaid Abassi ${ }^{1,2}$, Shadi Hamoud ${ }^{3}$, Ahmad Hassan ${ }^{4}$, Iyad Khamaysi ${ }^{5}$, Omri Nativ ${ }^{1}$, \\ Samuel N. Heyman 6 , Rabia Shekh Muhammad ${ }^{3}$, Neta Ilan7, Preeti Singh7, Edward \\ Hammond $^{8}$, Gianluigi Zaza99, Antonio Lupo ${ }^{9}$, Maurizio Onisto ${ }^{10}$, Gloria Bellin ${ }^{9}$, \\ Valentina Masola ${ }^{9}$, Israel Vlodavsky ${ }^{7}$ and Giovani Gambaro ${ }^{11}$ \\ ${ }^{1}$ Department of Physiology, The Rappaport Faculty of Medicine, Technion, Haifa, Israel \\ 2 Department of Laboratory Medicine, Rambam Health Care Campus, Haifa, Israel \\ ${ }^{3}$ Department of Internal Medicine E, Rambam Health Care Campus, Haifa, Israel \\ ${ }^{4}$ Department of Internal Medicine A, Rambam Health Care Campus, Haifa, Israel \\ ${ }^{5}$ Department of Gastroenterology, Rambam Health Care Campus, Haifa, Israel \\ ${ }^{6}$ Department of Internal Medicine, Hebrew University-Hadassah Medical Center, Jerusalem, Israel \\ 7 Department of Cancer and Vascular Biology Research Center, The Rappaport Faculty of Medicine, Technion, Haifa, Israel \\ ${ }^{8}$ Zucero Therapeutics, Brisbane, Queensland, Australia \\ ${ }^{9}$ Department of Medicine, Renal Unit, Verona, Italy \\ ${ }^{10}$ Department of Biomedical Sciences, University of Padova, Catholic University of the Sacred Heart, Roma, Italy \\ ${ }^{11}$ Department of Medicine, Columbus-Gemelli Hospital, Catholic University of the Sacred Heart, Roma, Italy \\ Correspondence to: Zaid Abassi, email: abassi@tx.technion.ac.il
}

Israel Vlodavsky, email: vlodavsk@cc.huji.ac.il

Keywords: acute kidney injury, heparanase, ischemia, inflammation, PG545

Received: February 09, $2017 \quad$ Accepted: March 16, $2017 \quad$ Published: March 25, 2017

Copyright: Abassi et al. This is an open-access article distributed under the terms of the Creative Commons Attribution License (CC-BY), which permits unrestricted use, distribution, and reproduction in any medium, provided the original author and source are credited.

ABSTRACT

Despite the high prevalence of acute kidney injury (AKI) and its association with increased morbidity and mortality, therapeutic approaches for AKI are disappointing. This is largely attributed to poor understanding of the pathogenesis of AKI. Heparanase, an endoglycosidase that cleaves heparan sulfate, is involved in extracellular matrix turnover, inflammation, kidney dysfunction, diabetes, fibrosis, angiogenesis and cancer progression. The current study examined the involvement of heparanase in the pathogenesis of ischemic reperfusion (I/R) AKI in a mouse model and the protective effect of PG545, a potent heparanase inhibitor. I/R induced tubular damage and elevation in serum creatinine and blood urea nitrogen to a higher extent in heparanase over-expressing transgenic mice vs. wild type mice. Moreover, TGF- $\beta$, vimentin, fibronectin and a-smooth muscle actin, biomarkers of fibrosis, and TNFa, IL6 and endothelin-1, biomarkers of inflammation, were upregulated in I/R induced AKI, primarily in heparanase transgenic mice, suggesting an adverse role of heparanase in the pathogenesis of AKI. Remarkably, pretreatment of mice with PG545 abolished kidney dysfunction and the up-regulation of heparanase, pro-inflammatory (i.e., IL-6) and pro-fibrotic (i.e., TGF- $\beta$ ) genes induced by I/R. The present study provides new insights into the involvement of heparanase in the pathogenesis of ischemic AKI. Our results demonstrate that heparanase plays a deleterious role in the development of renal injury and kidney dysfunction, attesting heparanase inhibition as a promising therapeutic approach for AKI. 


\section{INTRODUCTION}

Acute kidney injury (AKI) is a common clinical disorder affecting $2-7 \%$ of hospitalized patients and some $20-50 \%$ of critically ill subjects $[1,2]$. Renal ischemia and hypoxia, toxic insult and sepsis are the leading causes of clinical AKI $[1,2]$. Specifically, AKI is characterized by decreased oxygen delivery, depletion of cellular energy stores and accumulation of toxic metabolites. The cellular depletion of ATP, a hallmark of ischemic injury, leads to a series of morphological, biochemical and physiological derangements [2-4]. Reperfusion of ischemic tissue, although necessary for repair, has been shown to exacerbate AKI owing to the generation of reactive oxygen and nitrogen species [2-6]. Despite the advances in critical care medicine, AKI is still associated with high morbidity and mortality assumedly due to delayed detection of the disease and lack of effective treatment [7].

Several strategies were proposed to deal with AKI $[2,3,8]$. Among these are antioxidants including acetylcysteine, antioxidant enzyme mimetics, erythropoietin, peroxisome-proliferator-activated receptor agonists, inhibitors of poly(ADP-ribose) polymerase, carbon monoxide-releasing molecules and other measures to enhance hypoxia inducible factors, statins, and adenosine $[2,3,6]$. Unfortunately, the clinical efficacy of these therapeutic approaches is inconsistent and disappointing. Therefore, there is a great need to improve our understanding of the pathogenesis of AKI and design new strategies to prevent kidney damage during AKI.

Heparan sulfate (HS) proteoglycans (HSPGs) are ubiquitous macromolecules associated with the cell surface and extracellular matrix (ECM) of a wide range of tissues including the kidney [9]. The HS chains bind to and assemble ECM proteins, thus playing important roles in ECM integrity, barrier function, and cell-ECM interactions [9]. HSPGs not only provide a storage depot for heparin binding molecules (i.e., growth factors, chemokines, enzymes) in the tissue microenvironment, but also regulate their accessibility, function and mode of action. It is therefore not surprising that a HS degrading enzyme, heparanase, is critically involved in pathological processes, including tumor growth, metastasis, angiogenesis, thrombosis, fibrosis, inflammation, autoimmunity and kidney dysfunction [10-18].

Emerging evidence suggests the involvement of heparanase in diabetic and nondiabetic proteinuric kidney diseases $[19,20]$. For example, heparanase expression was shown to be upregulated in a number of animal models of renal diseases, including passive Heymann nephritis [21], puromycin aminonucleoside nephrosis (PAN) [22], adriamycin nephropathy (ADR-N) [23, 24], anti-glomerular basement membrane (GBM) nephritis [25], and diabetic nephropathy [26]; and in glomerular epithelial and endothelial cells cultured in ambient high glucose concentration [27]. As expected, heparanase upregulation was associated with reduced HS size in the GBM [20, 28]. Likewise, increased heparanase activity was detected in urine samples from diabetic patients with microalbuminuria [20, 27, 29-31], nondiabetic nephrotic syndrome, chronic kidney diseases (CKD) and kidney transplanted patients [29]. Notably, neutralization of heparanase activity, using either a sulfated oligosaccharide inhibitor (PI-88) or anti-heparanase antibodies, resulted in reduced proteinuria in ADR-N [32]. Similarly, Gil and colleagues [33] demonstrated that heparanase null mice fail to develop albuminuria and renal damage in response to streptozotocin-induced diabetes mellitus. Furthermore, a lower degree of albuminuria was detected in type 1 and type 2 diabetic mice treated with a heparanase inhibitor $($ SST0001 $=$ Roneparstat) $v s$. mice treated with vehicle alone [33].

Although heparanase is recognized for its important role in diabetic nephropathy and other progressive CKD [34], its direct involvement and mode of action in the pathogenesis of AKI has not been studied thoroughly. We have previously reported that heparanase is involved in the onset and development of I/R-induced epithelial to mesenchymal transition (EMT) both in vitro and in vivo [35] and Lygizos et al [36] found that glomerular heparanase is activated during sepsis and contributes to septic AKI. Elucidation of the mechanism underlying the function of heparanase in AKI is critically important for the proper design of novel therapeutics approaches, including heparanase inhibitors such as PG545, Roneparstat and other compounds currently under intensive development and clinical testing [17, 37]. PG545, a synthetic fully sulfated HS mimetic with potent, long acting heparanase inhibiting capacity [38,39], ended phase I clinical trial in cancer patients. The availability of PG545 and of heparanase over-expressing transgenic mice (Hpa-tg) [40] provides a most appropriate experimental platform to elucidate the involvement of heparanase in the pathogenesis of AKI. We report that PG545 abolished kidney dysfunction and the up-regulation of heparanase, pro-inflammatory (i.e., IL-6) and pro-fibrotic (i.e., TGF- $\beta$ ) mediators induced by I/R AKI.

\section{RESULTS}

\section{Acute ischemic injury up-regulates renal heparanase expression and enzymatic activity}

Acute ischemic injury was induced by clamping both renal arteries for 30 minutes. As previously described [35], real-time PCR analyses (Figure 1A) confirmed an increment of heparanase expression in renal tissue of $w t$ mice $48 \mathrm{~h}$ after ischemia and a more pronounced effect was noted in Hpa-tg mice at $72 \mathrm{~h}$. Immunofluorescence 
staining of renal tissue of $w t$ animals confirmed that acute ischemic renal injury up-regulated heparanase in glomeruli, tubular cells and interstitial cells (Figure 1B). As demonstrated in Figure 1C, heparanase enzymatic activity was markedly enhanced following AKI in $w t$ mice. Thus, when incubated with sulfate-labeled ECM, extracts from kidney of $w t$ mice that were subjected to AKI released high amounts of HS degradation fragments (peak at fraction 23) as compared with sham control mice. As expected, kidney tissue from untreated Hpa-tg mice exhibited high basal heparanase activity (Figure 1D). These results are supported by qPCR analysis (Figure 1A) and immunostaining (Figure 1B) showing that heparanase expression and immunoreactivity were increased following AKI induction in both $w t$ and Hpa-tg mice. Importantly, when $w t$ and Hpa-tg mice were pretreated with PG545, heparanase gene expression (Figure 1A), immunoreactivity (Figure 1B) and enzymatic activity (Figure 1C, 1D) were profoundly suppressed, signifying the remarkable protective effect of PG545 against I/R.

\section{Heparanase induces acute ischemic injury}

\section{Histology}

The structural changes in the kidney tissue of control and I/R wt and Hpa-tg mice were evaluated by PAS staining. We confirmed that at $48 \mathrm{~h}$ after $\mathrm{I} / \mathrm{R}, w t$ mice
A

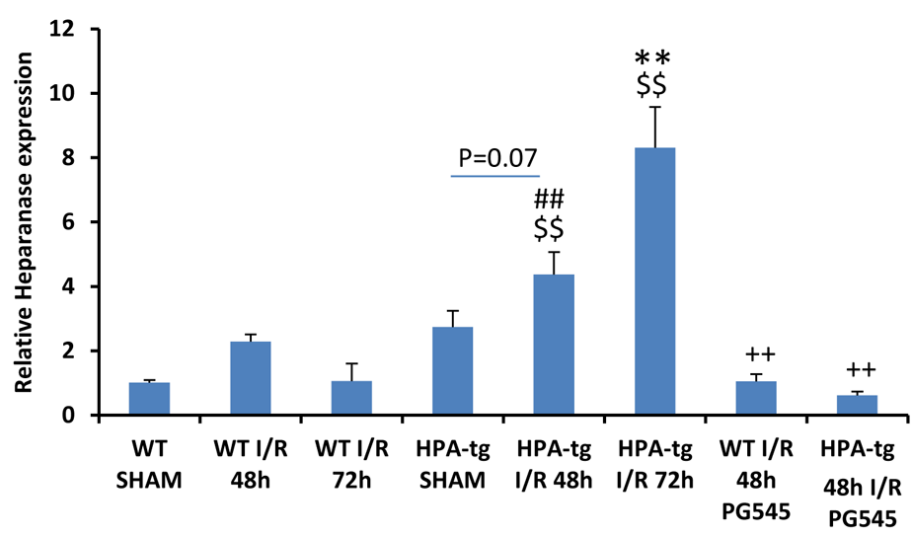

C

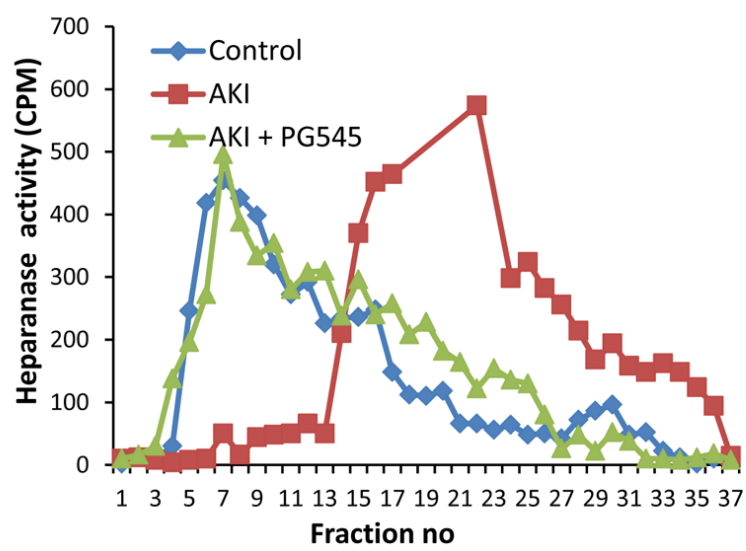

B
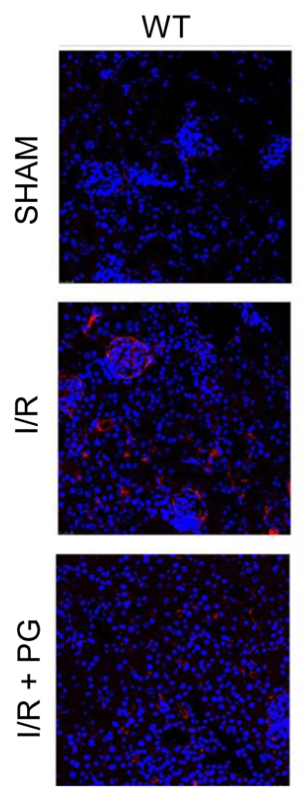

D

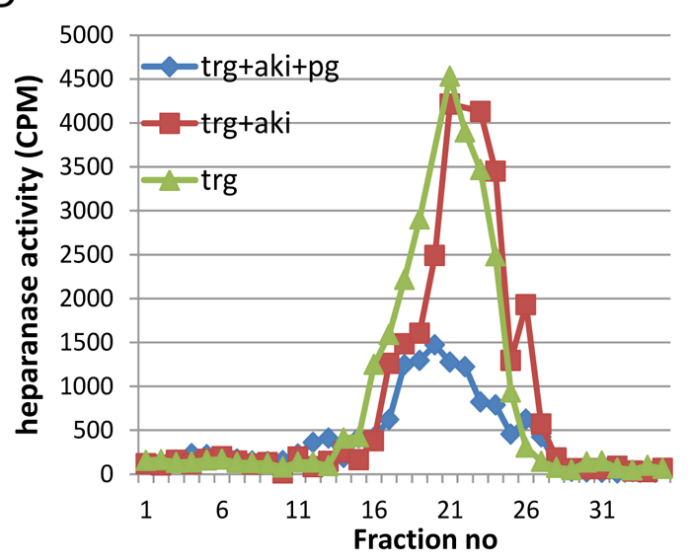

Figure 1: Heparanase regulation by I/R kidney injury. A. Bar plot showing relative gene expression of HPSE evaluated by real-time PCR in renal tissue extract from $w t$ and Hpa-tg mice untreated or pre-treated with PG545. Results were normalized to GAPDH expression. B. Representative immunofluorescence staining of heparanase in cortical renal tissues of $w t$ and $\mathrm{Hpa}$-tg mice $48 \mathrm{~h}$ after $\mathrm{I} / \mathrm{R}$ kidney injury, with or without pre-treatment with PG545. Magnification 40X. Representative heparanase activity in the renal tissue of $w t$ C. and Hpa-tg D. mice prior and post I/R in the presence or absence of PG545 pretreatment. I/R, ischemia/reperfusion. ${ }^{*} p<0.05, * * p<0.01$ $v s$. corresponding sham; $\# p<0.05, \# \# p 0.01 v s$. corresponding group w/o I/R ; $\$ p<0.05, \$ \$ p<0.01 v s$. corresponding wt; $+p<0.05$, $++p<0.01 v s$. untreated I/R corresponding group. 


\section{A}
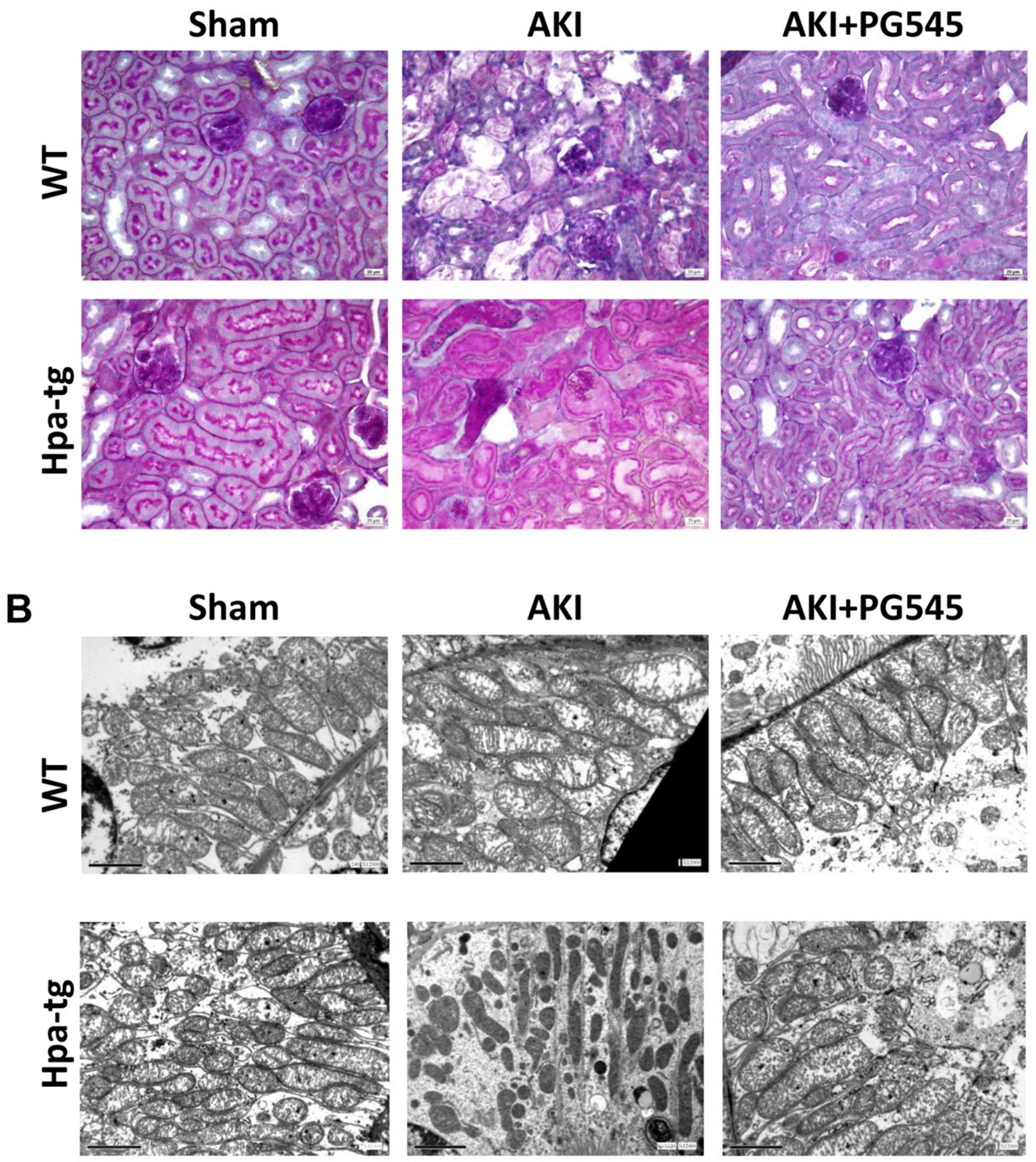

Figure 2: Ischemia/reperfusion (I/R) kidney injury in $w t$ and Hpa-tg mice. I/R kidney injury was induced in $w t$ and Hpa-tg mice by 30 minutes of clamping of both renal arteries. Mice were sacrificed after 48 hours. A. Representative images of PAS staining of paraffin-embedded cortex sections from various experimental groups. Magnification 40x. B. Electron microscopy micrographs of cortical renal tissue from $w t$ and Hpa-tg mice that were subjected to 30 minutes of clamping of both renal arteries in the absence or presence of PG545 (0.4 mg/mouse, i.v). Note mitochondrial swelling and damage to mitochondrial cristae. Note normal ultrastructural appearance of mitochondria from mice treated with PG545. Magnification 12,000×. 
showed acute tubular necrosis which included tubular lysis, loss of brush border and sloughed debris in the tubular lumen spaces (Figure 2A). While in $w t$ mice the damage was partially attenuated after $72 \mathrm{~h}$, the injury in Hpa-tg mice was more profound and persistent also after $72 \mathrm{~h}$ (not shown). In Hpa-tg mice there was a significant alteration in glomeruli and tubular structures. In particular, in Hpa-tg mice I/R produced a severe tubular damage with tubular dilatation, cell detachment from basement membrane, cast formation and loss of brush border (Figure 2A). Notably, these effects were partially prevented in response to pretreatment with PG545.

\section{Ultrastructure alterations}

Electron microscopy analyses of the renal tissue from the various experimental groups are presented in Figure 2B. As expected, induction of AKI resulted in

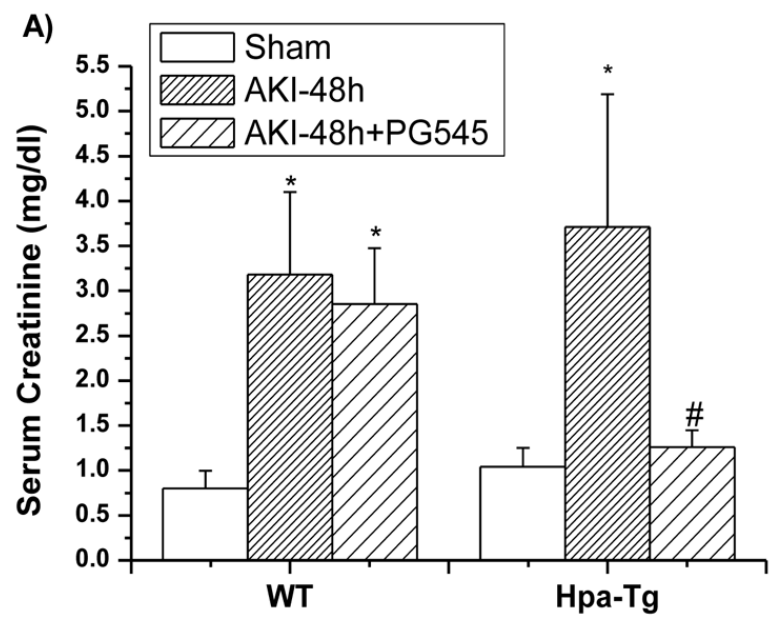

C)

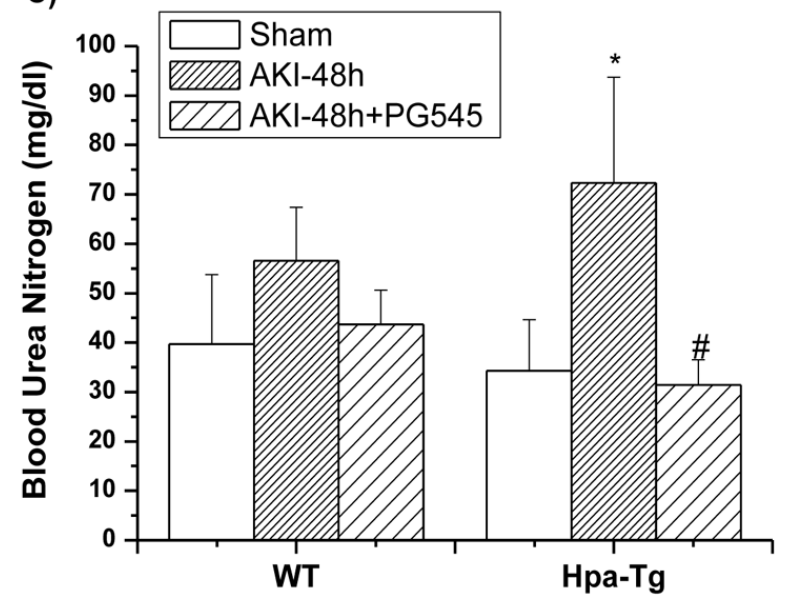

remarkable mitochondrial alterations. Specifically, the mitochondria in the tubular cells of control wt and Hpatg mice exhibited elongated cylindrical shape, whereas induction of AKI in both $w t$ and Hpa-tg mice resulted in fragmented mitochondria and transformation from filamentous shape into short rods (Figure 2B). These deleterious alterations were more profound in Hpa-tg mice as was evident by spherical shape and matrix vacuoles (cristolysis). Pretreatment with PG545 of either $w t$ or Hpa-tg mice partially restored the tubular mitochondrial morphological changes induced by AKI (Figure 2B) as was evident by nearly normal ultrastructural appearance of the mitochondrial cristae (Figure 2B).

\section{Kidney function}

Besides the histological changes, we further determined kidney function by measuring blood urea
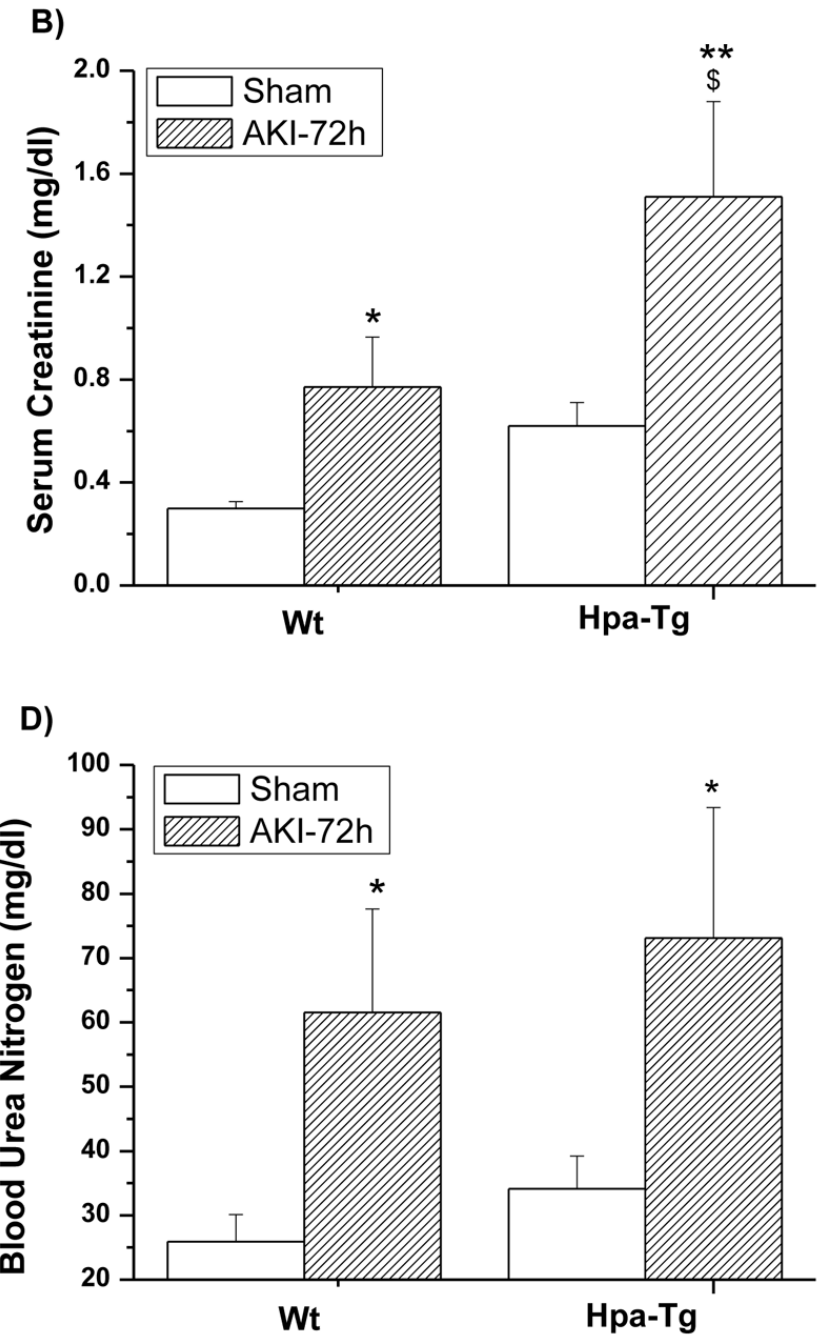

Figure 3: Biomarkers of kidney function in wt and Hpa-Tg mice after I/R. Effect of AKI on serum creatinine (SCr) A., B. and Blood urea nitrogen (BUN) C., D. 48 h A., C. and 72 h B., D. after I/R insult in $w t$ and Hpa-tg mice. Note that AKI induced a more profound increase in both SCr and BUN in Hpa-tg mice as compared with $w t$ mice. Additional two groups of $w t$ and Hpa-tg mice were pretreated one day prior to AKI induction with PG545 (0.4 mg/mouse, ip) and sacrificed $48 \mathrm{~h}$ after renal injury A., C. * $p<0.05, * * p<0.01 v s$. sham; $\# p$ $<0.01$ vs. untreated mice; $\$ p<0.05$ vs. wt. 
nitrogen (BUN) and serum creatinine ( $\mathrm{SCr}$ ) in the studied experimental groups (Figure 3). Induction of AKI in both $w t$ and Hpa-tg mice was characterized by significant elevation of serum creatinine ( $\mathrm{SCr}$ ) (Figure 3A, 3B) and blood urea nitrogen (BUN) (Figure 3C, 3D), which was evident after $48 \mathrm{~h}$ and $72 \mathrm{~h}$ in both the $w t$ and Hpa-tg mice (Figure 3), but was more prominent in the Hpa-tg mice after $72 \mathrm{~h}$ (Figure 3B, 3D). Pretreatment with PG545 attenuated the elevation of $\mathrm{SCr}$ and BUN in the Hpa-tg mice (Figure 3A, 3C).

\section{Heparanase inhibition attenuates epithelial mesenchymal transition}

Gene expression analysis of total kidney lysates and immunofluorescence staining for $\alpha$-SMA (Figure 4A, 4B), vimentin (Figure 4C, 4D) and fibronectin (Figure $4 \mathrm{E}, 4 \mathrm{~F}$ ) showed a slight or no up-regulation following acute ischemic renal insult in $w t$ mice. In contrast, Hpa-tg mice displayed a significant and early activation of these parameters. Specifically, while in $w t$ mice $\alpha$-SMA (Figure 4A) and vimentin (Figure 4C) expression in the kidney were slightly increased $48 \mathrm{~h}$ after acute renal ischemia and returned to basal levels after $72 \mathrm{~h}$, Hpa-tg mice exhibited remarkable up regulation of SMA (Figure 4A), vimentin (Figure 4C) and FN (Figure 4E), both at 48 and $72 \mathrm{~h}$. Similarly, we have previously reported the involvement of heparanase in epithelial mesenchymal transition, both in vitro and in vivo (35). Importantly, pretreatment with PG545 abolished the elevation in $\alpha$-SMA, vimentin and fibronectin in the Hpa-tg mice (Figure 4A, 4C, 4E). Immunofluorescent staining confirmed the gene expression pattern on the protein level (Figure 4B, 4D, 4F), altogether emphasizing the involvement of heparanase in renal $\mathrm{I} / \mathrm{R}$ and the associated epithelial mesenchymal transition.

\section{Heparanase affects TGF- $\beta$, ET-1, IL6, TNF $\alpha$ and cathepsin $L$ expression}

In $w t$ mice, 48 and $72 \mathrm{~h}$ after ischemia, TGF- $\beta$ mRNA levels were similar to sham operated animals. In contrast, in Hpa-tg mice, acute I/R injury induced significant up-regulation of the TGF- $\beta$ gene at both $48 \mathrm{~h}$ and $72 \mathrm{~h}$ (Figure 5A). A similar pattern of ET-1 (Figure 5B) and IL6 (Figure 5C) upregulation was observed in Hpa-tg, but not $w t$ mice that were subject to AKI, yet the upregulation of these genes was significant only at $72 \mathrm{~h}$. Induction of AKI in $w t$ and Hpa-tg mice was also associated with enhanced expression of TNF $\alpha$ (Figure 5D) and cathepsin L (Figure 5E), a key enzyme in the processing and activation of latent heparanase [41]. Again, the increased expression of these two genes was more profound in Hpa-tg mice. Remarkably, pretreatment with PG545 abolished the elevation in TGF $\beta$, and to a lesser extent the upregulation of ET-1, IL-6, cathepsin L and
TNF $\alpha$. Altogether, it appears that biomarkers of fibrosis, EMT and inflammation were upregulated in $\mathrm{I} / \mathrm{R}$ induced AKI, primarily in Hpa-tg mice, and this elevation was prevented to a large extent following pretreatment with PG545.

\section{DISCUSSION}

Despite the high prevalence of AKI and its association with an alarming increase in morbidity and mortality, the therapeutic approaches for AKI are still disappointing and rely mainly on supportive measures. This deficiency stems mainly from the poor understanding of the pathogenesis of AKI. The current research is therefore of special significance since it provides new insights into the mechanism underlying ischemic AKI, a major etiology of AKI. Specifically, we demonstrated that $\mathrm{I} / \mathrm{R}$ of the kidney induced renal injury in both $w t$ and Hpatg mice as was evident by typical tubular damage including cell lysis, loss of brush border and sloughed debris in tubular lumen, which was more profound in Hpa-tg mice (Figure 2). The latter also displayed exaggerated elevation in $\mathrm{SCr}$ and BUN. Moreover, TGF- $\beta$, fibronectin, vimentin and $\alpha$-smooth muscle actin, biomarkers of epithelial mesenchymal transition [35, 42], were upregulated in I/R induced AKI, especially in Hpa-tg mice, indicating an adverse role of heparanase in the pathogenesis AKI. This notion is further supported by the fact that pretreatment with PG545, a potent long acting inhibitor of heparanase [38], abolished the adverse renal changes induced by I/R and improved kidney function. Collectively, these findings clearly implicate heparanase in the pathophysiology of AKI, and suggest heparanase inhibitors as preventive/ therapeutic option for this common clinical setting. Given that transgenic mice may differ from their $w t$ counterparts in various aspects, each experiment was performed with both $w t$ and Hpa-tg mice, yielding the same results (i.e., upregulation of biomarkers of fibrosis, inflammation and EMT and down regulation/protection by the heparanase inhibitor PG545), albeit to a lower extent in $w t$ mice. Overall it appears that the disease model is operating in $w t$ mice in a manner similar to that seen in Hpa-tg mice.

Despite the remarkable advances in nephrology, the pathophysiology of AKI remains largely obscured. Thus, research involving genetically modified animal models is a critical step in providing a new perspective into the pathophysiology of AKI. Indeed, the Hpa-tg mouse model [40] provides an appropriate experimental platform to elucidate the involvement of heparanase in the pathogenesis of AKI. Of note, Hpa-tg mice revealed increased levels of urinary creatinine at baseline, indicating a slight effect of heparanase on renal function even without induction of AKI (40), although this increase did not reach statistical significance as compared with wt mice (Figure 3). This result further supports the involvement of heparanase in kidney dysfunction, 


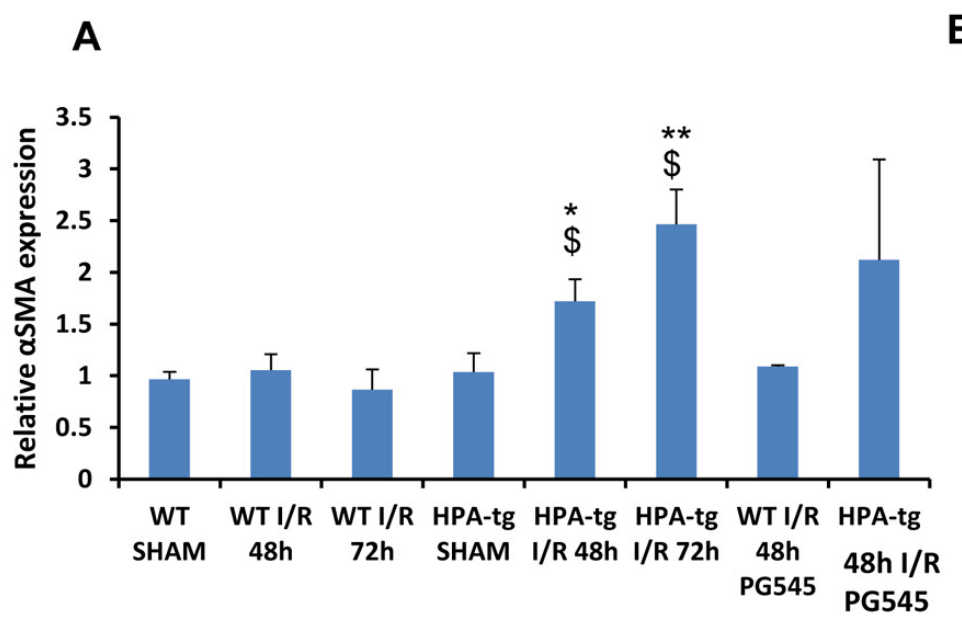

B
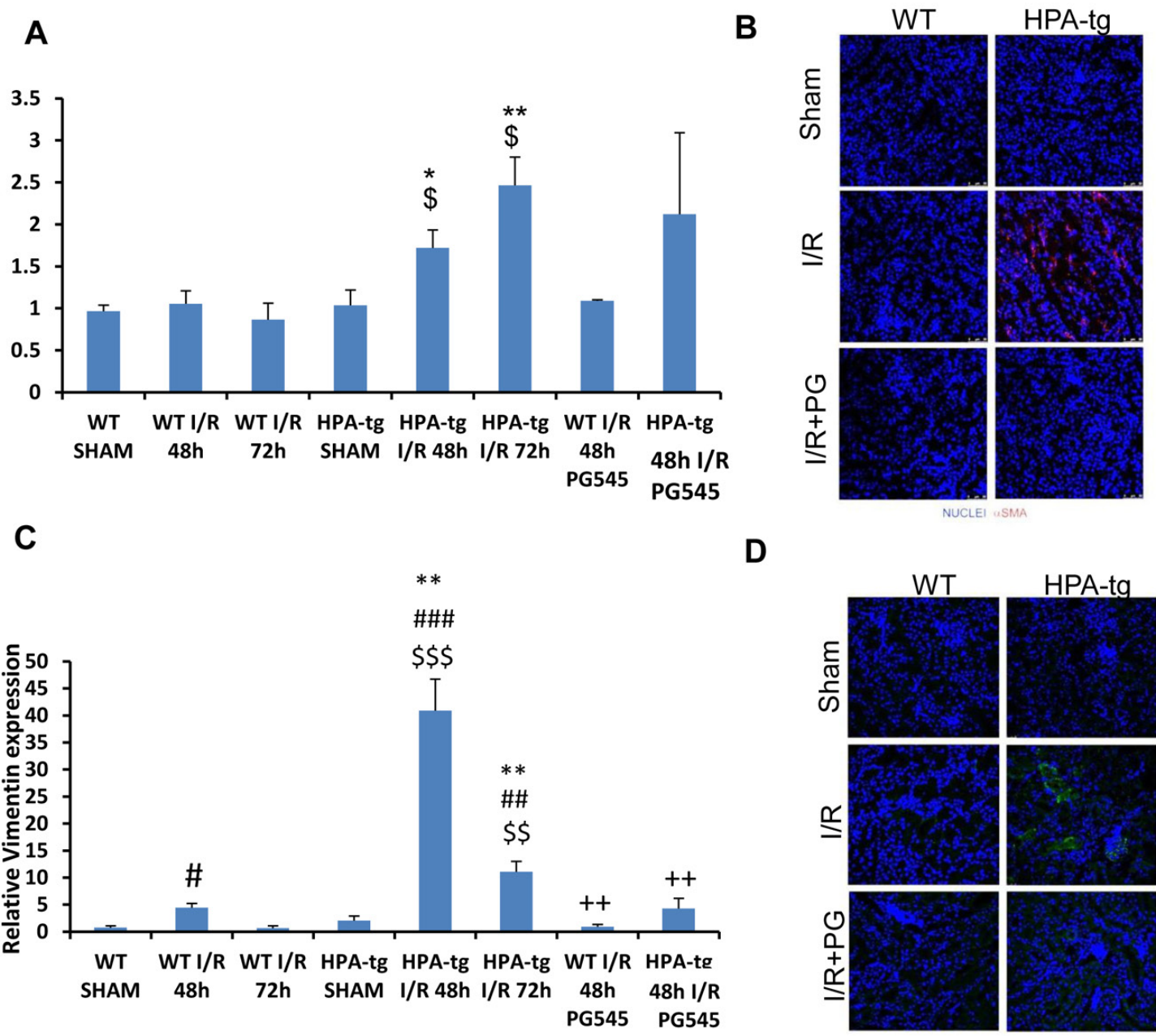

E

D
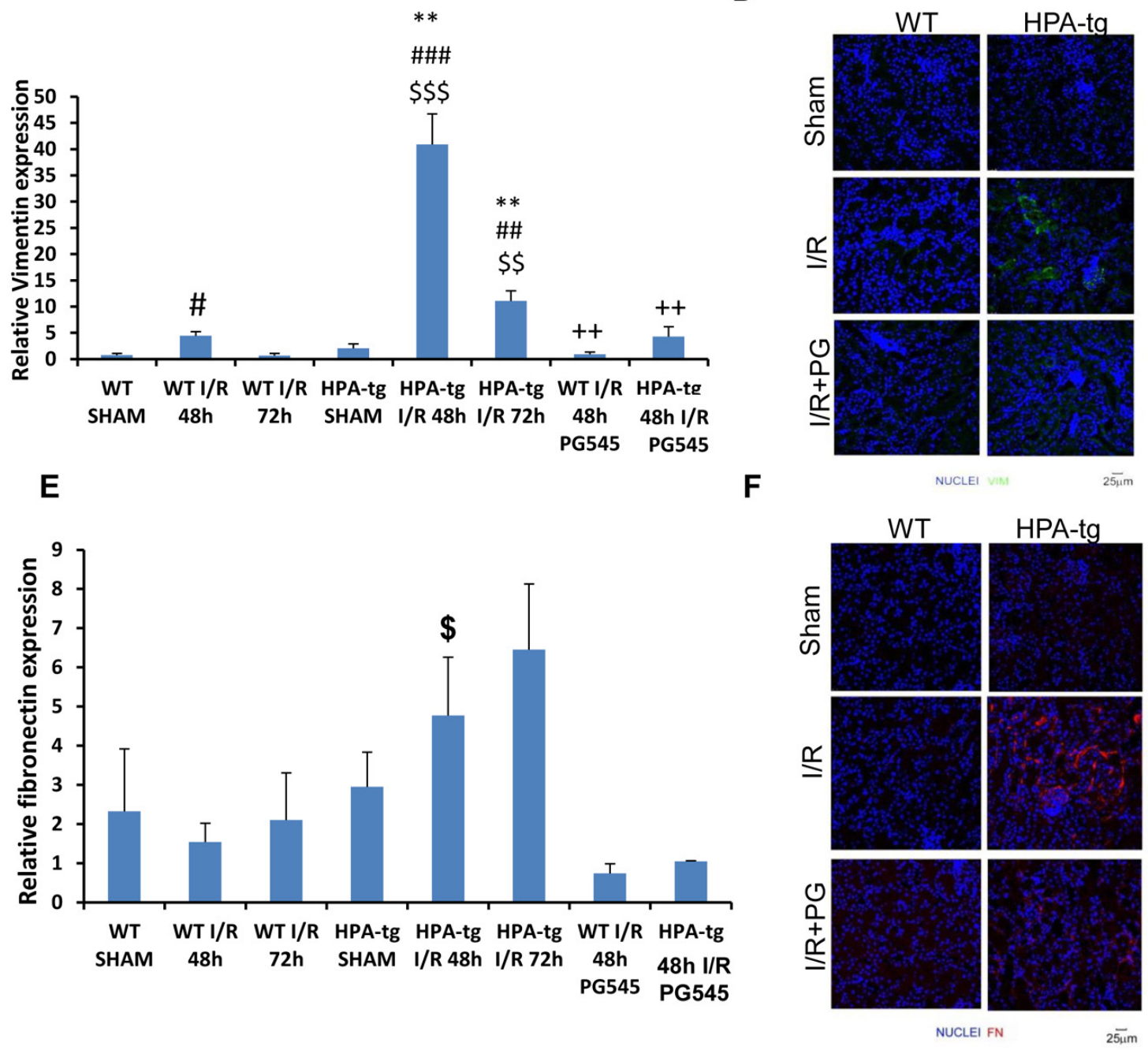

Figure 4: Expression of epithelial mesenchymal transition (EMT) markers in wt vs. Hpa-tg mice after I/R kidney injury. Relative gene expression of A. $\alpha$-SMA, C. VIM, and E. FN, were evaluated by real-time PCR in renal tissue extracts from $w t$ and Hpa-tg mice that underwent I/R kidney injury with or without pre-treatment with PG545. Results were normalized to GAPDH expression. ** $p<$ 0.001 vs. wt SHAM mice. I/R, ischemia/reperfusion. Representative immunofluorescence staining of $\alpha$-SMA B., VIM D. and FN F. in renal tissue of $w t$ and Hpa-tg mice that underwent $48 \mathrm{~h}$ of I/R kidney injury with or without pre-treatment with PG545. Magnification $40 \mathrm{x} .{ }^{*} p<$ $0.05,{ }^{* *} p<0.01 v s$. corresponding sham; $\# p<0.05$, \#\#p $<0.01$ vs. corresponding group w/o I/R; $\$ p<0.05$, $\$ \$ p<0.01 v s$. corresponding $\mathrm{wt} ;+p<0.05,++p<0.01$ vs. untreated I/R corresponding group. 
showing that the heparanase level in Hpa-tg mice is by itself not enough to induce acute damage, whereas its combination with $\mathrm{I} / \mathrm{R}$ results in AKI to a higher extent in Hpa-tg than in wild type mice. Similar to other heparanase-inhibiting heparin-like compounds PG545 displays some anti-coagulant properties, but this side effect was not detected in the AKI model nor in numerous tumor models in which mice are treated with PG545 for weeks [38]. Also, PG545 was found safe in phase I clinical trial in cancer patients $[17,37]$. Our preliminary studies indicate that administration of PG545 post I/R failed to restore kidney damage and function. Yet, our pre-treatment approach maybe of clinical relevance in cases where AKI may occur (i.e., patients who undergo imaging involving i.v radiocontrast administration; patients undergoing major vascular surgery and cardiopulmonary bypass). So far there is no effective preventive treatment to minimize the incidence of AKI under these and other clinical settings, suggesting that PG545 may constitute a novel prophylactic therapeutic approach.

Unlike the Hpa-tg mice, results obtained with heparanase knockout mice [43] were not straightforward. AKI was induced by $\mathrm{I} / \mathrm{R}$ also in the Hpa-KO mice, albeit to a lower extent than in $w t$ and Hpa-tg mice, as revealed by the respective BUN and creatinine values. We have previously reported that the Hpa-KO mice reveal compensations for the lack of heparanase. These include up-regulation of matrix degrading enzymes and pro-
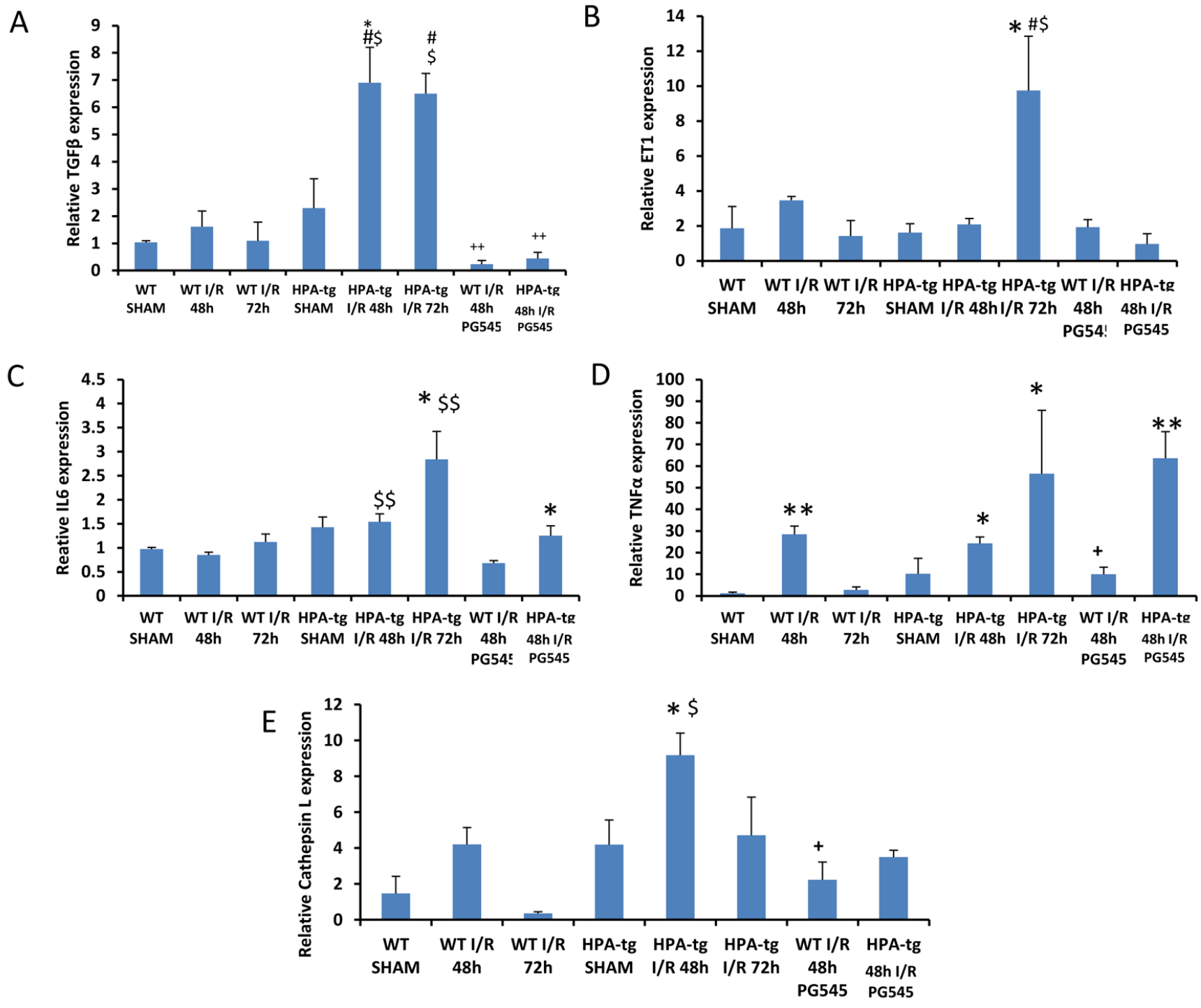

Figure 5: TGF- $\beta$, ET-1, IL6, TNF $\boldsymbol{\alpha}$ and cathepsin L gene expression in $\boldsymbol{w} \boldsymbol{t} \boldsymbol{v s .}$ Hpa-tg mice after I/R kidney injury. Bar plots representing relative gene expression of TGF- $\beta$ A., ET-1B., IL6 C., TNF $\alpha$ D. and Cathepsin L E., evaluated by real-time PCR in renal tissue extracts from $w t$ and Hpa-tg mice that underwent I/R kidney injury with or without pre-treatment with PG545. Results were normalized to GAPDH expression. ${ }^{*} p<0.05,{ }^{*} p<0.001 v s$. wt sham; $\# p<0.05$, \#\#p $<0.01 v s$. corresponding group w/o I/R; $\$ p<0.05, \$ \$ p<0.01 v s$. corresponding wt; $+p<0.05,++p<0.01$ vs. untreated I/R corresponding group. 
inflammatory mediators [43], resulting, paradoxically, in several phenotypes that closely resemble phenotypes seen in the Hpa-tg mice, making it difficult to interpretate data obtained with the Hpa-KO mice.

The availability of PG545 allows exploring potential therapeutic effects of heparanase inhibition in AKI. The latter is of special interest since in contrast to the well-established association between heparanase and glomerular diseases [20, 28], the role of heparanase in renal EMT associated with $\mathrm{I} / \mathrm{R}$ injury has only recently been addressed [35]. Notably, a role for heparanase was identified in several proteinuric nephropathies [20, 23, 28], mainly in the pathogenesis of diabetic nephropathy $[26,33]$ and in a model of septic AKI [36]. The latter is not surprising in light of the emerging data linking heparanase and inflammatory responses, suggesting a role of this enzyme in AKI. Indeed, Lygizos et al [36] found that glomerular heparanase is activated during sepsis and contributes to septic AKI. Specifically, the authors induced polymicrobial sepsis in mice using cecal ligation and puncture (CLP) in the presence or absence of competitive heparanase inhibitors (heparin or nonanticoagulant $\mathrm{N}$-desulfated re-N-acetylated heparin). CLP-treated mice demonstrated early activation of glomerular heparanase with coincident loss of glomerular function, as indicated by an increase in blood urea nitrogen (BUN) and decrease in GFR. Administration of heparanase inhibitors two hours prior to CLP attenuated the deleterious consequences of sepsis, suggesting that glomerular heparanase is active during sepsis and contributes to septic renal dysfunction via uncharacterized mechanisms. In line with these findings, bilateral renal ischemia/reperfusion $(\mathrm{I} / \mathrm{R})$ in syndecan-1 deficient mice resulted in increased initial renal failure and tubular injury compared with $w t$ mice [44]. In additional study, these authors have shown that within $24 \mathrm{~h}$ after renal I/R, HSPGs expressed at the abluminal side of peri-tubular capillaries are induced to bind L-selectin and the monocyte chemoattractant protein-1, and that HSPGs facilitate monocyte extravasation [45]. A vicious circuit of heparanase-driven molecular events promoting chronic inflammation and renal injury has recently been described $[11,33]$. This circuit is fueled by heterotypic interactions among glomerular, tubular, and immune cell compartments. It appears that latent heparanase, over-expressed by glomerular, epithelial and interstitial cells and post-translationally activated by cathepsin L, sustains continuous activation of kidneydamaging macrophages via degradation of HS and release of chemokines anchored within the ECM network and cell surfaces [11]. Moreover, active heparanase governs macrophage activation via HS degradation fragments which activate TLR2 and TLR4 [46], leading to increased levels of TNF- $\alpha$ thereby creating inflammatory conditions fostering macrophage-mediated renal injury and upregulation of heparanase expression. This scenario is further supported by our findings. First, Hpa-tg mice were more susceptible to I/R-induced renal damage and kidney dysfunction as compared with their wt counterparts subjected to the same surgical maneuver. Second, using gene silencing approaches we further revealed an essential involvement of heparanase in the development of I/R-induced epithelial damage and suggested that its inhibition may signify a therapeutic approach to minimize/ prevent ischemic-induced renal fibrosis $[35,47]$. Both, our previous in vitro studies applying cultured epithelial cells that were subjected to I/R $[35,47]$ and the current in vivo ischemic AKI model in wt and Hpa-tg mice exhibited upregulation of heparanase along over-expression of proinflammatory and pro-fibrotic cytokines (i.e., TGF- $\beta$, IL-6, $\mathrm{TNF} \alpha$ ) as well as markers of EMT (i.e., VIM, FN, $\alpha \mathrm{SMA}$ ). Activated macrophages secrete TNF $\alpha$ and cathepsin L, which stimulate further production and activation of heparanase by these cells and by ischemia-induced renal injured cells.

Upregulation of the TGF- $\beta$ gene suggests that I/R triggers renal fibrogenesis, most likely through epithelialmesenchimal transition (EMT) of tubular cells [48]. Hparanase seems to play a major role in these processes as was evident by the exaggerated overexpression of TGF- $\beta$ in Hpa-tg mice exposed to I/R. While the critical causal involvement of TGF- $\beta$ in EMT and tissue fibrosis is well documented [42, 49], little is known about a crosstalk between heparanase and TGF- $\beta$ [48]. Even more so, a crosstalk between heparanase and ET-1 $[50,51]$ in AKI has not been reported. Evidence for the combined involvement of heparanase, TGF- $\beta$ and ET-1 in the fibrosis/inflammatory response to AKI is provided by showing that treatment with PG545 prior to I/R maintained a normal epithelial phenotype and abolished the EMT transcriptional program exemplified by a marked decrease in the levels of VIM, FN, $\alpha$-SMA, IL-6, ET- 1 and TGF- $\beta$. PG545, a potent heparin-like inhibitor of heparanase enzymatic activity, markedly decreases the ability of heparanase to release and potentiate the activity of ECMbound growth factors [37], further supporting PG545 as potential anti-fibrotic and kidney protective drug. Downregulation of heparanase expression in response to PG545 was noted in 4T1 breast carcinoma model [52]. This effect was attributed in part to inhibition of growth factorstimulated ERK activation by PG545 and the resulting inhibitory effect on the transcription factor early growth response 1 (EGR1), known to induce heparanase gene expression [53]. Given the multi target genes regulated by EGR1 [54], the same mechanism may explain the effect of PG545 on the expression TGF- $\beta$, TNF- $\alpha$, fibronectin and possibly other cytokines. Similarly, we have recently reported that heparanase activates Erk, p38 and JNK signaling, leading to increased c-Fos levels and induction of cytokine expression [55]. Suppression of this cascade by PG545 may affect the transcription of multiple genes including heparanase.

One of the studied parameters that might be of special relevance to kidney damage is ET-1, a vasoconstrictor released by endothelial cells [56]. ET-1 
acts via two receptors subtypes ETA and ETB to modulate vasoconstriction, proliferation, inflammation, ECM production, and fibrosis in various target organs including the kidney $[57,58]$. An evidence for the deleterious role of ET-1 in renal damage is derived from the nephroprotective effects of ET-1 antagonists in experimental and clinical models of AKI [59]. Previous studies have demonstrated a linkage between ET-1 and heparanase [60]. Such an association is essential for the development of DN, as was proven by the observation that heparanase-deficient mice were protected against diabetes-induced proteinuria and renal damage [33]. Addition of ET-1 increased heparanase mRNA expression and enzymatic activity in cultured podocytes [60]. Our results clearly show a positive correlation between renal heparanase and ET-1. Both were upregulated during AKI and inhibition of heparanase was associated with a decline in ET-1, suggesting a causal relationship between ET-1 and heparanase during ischemic AKI.

In summary, our results indicate that heparanase is involved in the pathogenesis of ischemic AKI. Moreover, we demonstrated that pretreatment with a potent heparanase inhibitor (PG545) exerts nephroprotective effect against this clinical setting. Thus, our study provides a better perspective on the pathogenesis of AKI and the potential development of therapeutic/preventive interventions.

\section{MATERIALS AND METHODS}

\section{Animal model}

Studies were conducted on $w t(\mathrm{Balb} / \mathrm{c})$ and corresponding heparanase-overexpressing (Hpa-tg) mice weighing 23-30 gr and maintained on standard rat chow and water ad libitum. Mice were crossed for over 10 generations with $\mathrm{Balb} / \mathrm{c}$ wt mice to produce pure genetic background. The Hpa-tg mice appeared normal and exhibited a normal life span and breeding behavior [40]. Western blot analysis revealed high expression of heparanase in the liver and kidney vs. low expression in the spleen of Hpa-tg vs. control mice [40, 61]. The study was performed according to the guidelines of the Animal Use and Care Committee, Technion (Haifa), and according to the Guide for the Care and Use of Laboratory Animals (NIH Publication no. 85-23, 1996) as approved by the local committee for supervision of animal experiments.

\section{Induction of renal ischemia}

Acute ischemia was induced in $w t(\mathrm{Balb} / \mathrm{c})$ and Hpa-tg mice as described by Mishra et al [62]. Wt and Hpa-tg mice were anesthetized with sodium pentobarbital $(50 \mathrm{mg} / \mathrm{kg}, \mathrm{IP})$ and placed on a controlled heating table, keeping the body temperature at $37^{\circ} \mathrm{C}$. Both right and left renal arteries were exposed and clamped for $30 \mathrm{~min}$ during which time the kidney was kept warm and moist. The clamp was then removed, the kidney was observed for the return of blood flow, and the abdominal wall incision was sutured. Mice were allowed to recover in a warmed cage for 48 and $72 \mathrm{~h}$ and blood samples were obtained at each time point for measurement of creatinine and urea. At these time points, kidney dysfunction and renal damage peak, especially $48 \mathrm{~h}$ post I/R [63]. Additional groups of $w t$ and Hpa-tg mice were pretreated one day prior to AKI induction with PG545 (0.4 mg/mouse, ip). The kidneys were harvested and weighted. One half of the left kidney was snap frozen in liquid nitrogen and stored at $-70^{\circ} \mathrm{C}$ until further molecular processing; the other half was fixed in formalin, paraffin-embedded, and sectioned $(4 \mu \mathrm{m})$. Paraffin sections were stained with hematoxylineosin and examined histologically. The right kidney was embedded in isopentane and frozen sections $(4 \mu \mathrm{m})$ were obtained for immunohistochemistry [35]. Sham operated mice that underwent an identical procedure except renal artery clamping, served as controls. The number of mice per group (n) ranged from 6 to 12 .

\section{Quantitative real-time PCR}

Total RNA was extracted with TRIzol (Sigma) and RNA (1 $\mu \mathrm{g})$ was amplified using one step PCR amplification kit, according to the manufacturer's (ABgene, Epsom, UK) instructions, essentially as described [55]. The moue primer sets used are listed in Table 1 .

\section{Immunofluorescence}

Sections $(4 \mu \mathrm{m})$ were cut from paraffin embedded tissue and non-specific binding sites were saturated for 1 h at $37^{\circ} \mathrm{C}$ with $\mathrm{PBS}, 5 \% \mathrm{BSA}$. Sections were incubated at $4{ }^{\circ} \mathrm{C}$ overnight with primary antibodies diluted in PBS supplemented with $1 \%$ BSA. The primary antibodies used were directed against vimentin (Santa Cruz sc-7557), fibronectin (Santa Cruz sc-9068), $\alpha$-SMA (Sigma A5228), or heparanase (Santa Cruz sc-25826). Primary antibodies were visualized with anti-mouse AlexaFluor-488, antigoat-FITC, anti-rabbit-Cy3, and anti-mouse-TR secondary antibodies. Cell nuclei were visualized by Hoechst 33258 . Images were obtained by a confocal LeicaSP 5 microscope [35].

\section{Heparanase activity}

Preparation of $\mathrm{Na}_{2}{ }^{35} \mathrm{SO}_{4}$-labeled ECM-coated 35$\mathrm{mm}$ dishes and determination of heparanase activity were performed essentially as described $[55,64]$. Briefly, freshly 
Table 1: Primers sequence list

\begin{tabular}{|l|l|l|}
\hline \multicolumn{1}{|c|}{ Gene } & \multicolumn{1}{c|}{ Forward 5'-3' } & \multicolumn{1}{c|}{ Reverse 5'-3' } \\
\hline GAPDH & GGCAAATTCAACGGCACAGT & GTCTCGCTCCTGGAAGATGG \\
\hline HPSE & CAAGAACAGCACCTACTCAAG & AGCAGTAGTCAAGGAGAAGC \\
\hline$\alpha$-SMA & TGCTGGACTCTGGAGATGGT & ACGAAGGAATAGCCACGCTC \\
\hline VIM & TCCAGAGAGAGGAAGCCGAA & AAGGTCAAGACGTGCCAGAG \\
\hline TGF- $\beta$ & GTGTGGAGCAACATGTGGAACTCTA & CGCTGAATCGAAAGCCCTGTA \\
\hline ET-1 & TGCTGTTCGTGACTTTCC & TGTTGACCCAGATGATGTC \\
\hline IL6 & CTGCAAGAGACTTCCATCCAGTT & GAAGTAGGGAAGGCCGTGG \\
\hline TNFa & CATCTTCTCAAAATTCGAGTGACAA & TGGGAGTAGACAAGGTACAACCC \\
\hline Cathepsin L & GTGGACTGTTCTCACGCTCA & ATCCACGAACCCTGTGTCA \\
\hline
\end{tabular}

collected renal tissues were homogenized and extracted in phosphate/citrate buffer ( $\mathrm{pH}$ 5.2) by three cycles of freeze/thaw. Tissue lysates were incubated (overnight, $37^{\circ} \mathrm{C}$ ) with ${ }^{35} \mathrm{~S}$-labeled ECM. The incubation medium $(1 \mathrm{ml})$ containing sulfate-labeled degradation fragments was subjected to gel filtration on a Sepharose CL-6B column. Fractions $(0.2 \mathrm{ml})$ were eluted with PBS and their radioactivity was counted in a $\beta$-scintillation counter. Degradation fragments of HS side chains produced by heparanase are eluted at $0.5<\mathrm{Kav}<0.8$ (fractions 12-29). Nearly intact HSPGs released from the ECM are eluted just after the $\operatorname{Vo}(\operatorname{Kav}<0.2$, fractions 3-10) [59, 60]. These high molecular weight products are released by proteases that cleave the HSPG core protein.

\section{Electron microscopy}

Renal tissues from the various experimental groups were fixed in $3.5 \%$ glutaraldehyde and rinsed in $0.1 \mathrm{M}$ sodium cacodylate buffer, $\mathrm{pH}$ 7.4. Tissue blocks $\left(1 \mathrm{~mm}^{3}\right)$ were post-fixed with $2 \% \mathrm{OsO}_{4}$ in $0.2 \mathrm{M}$ cacodylate buffer for $1 \mathrm{~h}$, rinsed again in cacodylate buffer to remove excess osmium, immersed in saturated aqueous uranyl acetate, dehydrated in graded alcohol solutions, immersed in propylene oxide, and embedded in Epon 812. Ultrathin sections $(80 \mathrm{~nm})$ were mounted on 300 -mesh, thinbar copper grid, counterstained with saturated uranyl acetate and lead citrate. Sections were examined with a transmission electron microscope (Jeol 1011 JEM) at 80 KV.

\section{Chemical analyses}

Blood urea nitrogen and serum creatinine levels were determined using commercially available colorimetric kits (Cayman, Ann Arbor, MI; Bioassay Systems, Hayward, CA, respectively).

\section{Statistical analysis}

Mean \pm SEM of the real-time PCR data were calculated with Rest2009 software. Gene expression differences in mouse samples were analyzed by linear regression models with group (WT-sham, WT-I/R 48h, WT-I/R 72h, TG-sham, TG-I/R 48 h, TG-I/R 72 h) entered as a categorical variable. Bonferroni-corrected adjusted means and differences were computed using the WT-sham as the referent group. A Bonferroni-corrected p-value < 0.05 was considered as statistically significant.

\section{Author contributions}

Conceived and designed the experiments: $\mathrm{VM}, \mathrm{MO}$, GZ, SH, NI, IK, GG, IV, ZA. Performed the experiments: VM, PS, GZ, IK, SH, ON, NI, AH, RSM. Analyzed the data: VM, GZ, GG, MO, GB, IV, ZA, AL. Contributed reagents/materials/analysis tools: VM, GZ, EH, SH, GG, IV, ZA. Wrote the paper: VM, GZ, GG, IV, ZA.

\section{ACKNOWLEDGMENTS}

We are grateful to the Israeli Society of Nephrology for their financial support. This study was supported in part by a research grant awarded to I.V. by the Israel Science Foundation (grant 601/14); I. V. is a Research Professor of the ICRF. P.S. is supported by a postdoctoral fellowship awarded by the Israeli Council for Higher Education (PBC program). The authors are grateful for the professional help of Irena Minkov, Department of Pathology, Rambam Health Campus, Haifa, Israel.

\section{CONFLICTS OF INTEREST}

Edward Hammond is employed by Zucero Therapeutics, Darra, Queensland, Australia.

\section{Editorial note}

This paper has been accepted based in part on peerreview conducted by another journal and the authors' response and revisions as well as expedited peer-review in Oncotarget. 


\section{REFERENCES}

1. Bonventre JV, Yang L. Cellular pathophysiology of ischemic acute kidney injury. J Clin Invest. 2011; 121:42104221.

2. Schrier RW, Wang W, Poole B, Mitra A. Acute renal failure: definitions, diagnosis, pathogenesis, and therapy. J Clin Invest. 2004; 114:5-14.

3. Lameire N, Van Biesen W, Vanholder R. Acute renal failure. Lancet. 2005; 365:417-430.

4. Sheridan AM, Bonventre JV. Pathophysiology of ischemic acute renal failure. Contrib Nephrol. 2001; 132:7-21.

5. Agarwal A, Nick HS. Renal response to tissue injury: lessons from heme oxygenase-1 GeneAblation and expression. J Am Soc Nephrol. 2000; 11:965-973.

6. Chatterjee PK. Novel pharmacological approaches to the treatment of renal ischemia-reperfusion injury: a comprehensive review. Naunyn Schmiedebergs Arch Pharmacol. 2007; 376:1-43.

7. Chertow GM, Burdick E, Honour M, Bonventre JV, Bates DW. Acute kidney injury, mortality, length of stay, and costs in hospitalized patients. J Am Soc Nephrol. 2005; 16:3365-3370.

8. Heyman SN, Rosenberger C, Rosen S. Experimental ischemia-reperfusion: biases and myths-the proximal vs. distal hypoxic tubular injury debate revisited. Kidney Int. 2010; 77:9-16.

9. Bernfield M, Gotte M, Park PW, Reizes O, Fitzgerald ML, Lincecum J, Zako M. Functions of cell surface heparan sulfate proteoglycans. Annu Rev Biochem. 1999; 68:729777.

10. Goldberg R, Meirovitz A, Hirshoren N, Bulvik R, Binder A, Rubinstein AM, Elkin M. Versatile role of heparanase in inflammation. Matrix Biol. 2013; 32:234-240.

11. Goldberg R, Rubinstein AM, Gil N, Hermano E, Li JP, van der Vlag J, Atzmon R, Meirovitz A, Elkin M. Role of heparanase-driven inflammatory cascade in pathogenesis of diabetic nephropathy. Diabetes. 2014; 63:4302-4313.

12. Ilan N, Elkin M, Vlodavsky I. Regulation, function and clinical significance of heparanase in cancer metastasis and angiogenesis. Int J Biochem \& Cell Biol. 2006; 38:20182039.

13. Parish CR, Freeman C, Hulett MD. Heparanase: a key enzyme involved in cell invasion. Biochim Biophys Acta. 2001; 1471:M99-108.

14. Parish CR, Freeman C, Ziolkowski AF, He YQ, Sutcliffe EL, Zafar A, Rao S, Simeonovic CJ. Unexpected new roles for heparanase in Type 1 diabetes and immune gene regulation. Matrix biology. 2013; 32:228-233.

15. Secchi MF, Masola V, Zaza G, Lupo A, Gambaro G, Onisto M. Recent data concerning heparanase: focus on fibrosis, inflammation and cancer. Biomol Concepts. 2015; 6:415421.

16. Vlodavsky I, Beckhove P, Lerner I, Pisano C, Meirovitz A,
Ilan N, Elkin M. Significance of heparanase in cancer and inflammation. Cancer Microenviron. 2012; 5:115-132.

17. Vlodavsky I, Singh P, Boyango I, Gutter-Kapon L, Elkin M, Sanderson RD, Ilan N. Heparanase: From basic research to therapeutic applications in cancer and inflammation. Drug Resist Updat. 2016; 29:54-75.

18. Vreys V, David G. Mammalian heparanase: what is the message? J Cell Mol Med. 2007; 11:427-452.

19. Szymczak M, Kuzniar J, Klinger M. The role of heparanase in diseases of the glomeruli. Arch Immunol Ther Exp (Warsz). 2010; 58:45-56.

20. van den Hoven MJ, Rops AL, Vlodavsky I, Levidiotis $\mathrm{V}$, Berden JH, van der Vlag J. Heparanase in glomerular diseases. Kidney Int. 2007; 72:543-548.

21. Levidiotis V, Freeman C, Tikellis C, Cooper ME, Power DA. Heparanase Is Involved in the Pathogenesis of Proteinuria as a Result of Glomerulonephritis. J Am Soc Nephrol. 2004; 15:68-78.

22. Levidiotis V, Kanellis J, Ierino FL, Power DA. Increased expression of heparanase in puromycin aminonucleoside nephrosis. Kidney Int. 2001; 60:1287-1296.

23. Kramer A, van den Hoven M, Rops A, Wijnhoven T, van den Heuvel L, Lensen J, van Kuppevelt T, van Goor H, van der Vlag J, Navis G, Berden JH. Induction of glomerular heparanase expression in rats with adriamycin nephropathy is regulated by reactive oxygen species and the reninangiotensin system. J Am Soc Nephrol. 2006; 17:25132520 .

24. van den Hoven MJ, Waanders F, Rops AL, Kramer AB, van Goor H, Berden JH, Navis G, van der Vlag J. Regulation of glomerular heparanase expression by aldosterone, angiotensin II and reactive oxygen species. Nephrol Dial Transplant. 2009; 24:2637-2645.

25. Levidiotis V, Freeman C, Tikellis C, Cooper ME, Power DA. Heparanase inhibition reduces proteinuria in a model of accelerated anti-glomerular basement membrane antibody disease. Nephrology (Carlton). 2005; 10:167-173.

26. van den Hoven MJ, Rops AL, Bakker MA, Aten J, Rutjes N, Roestenberg P, Goldschmeding R, Zcharia E, Vlodavsky I, van der Vlag J, Berden JH. Increased expression of heparanase in overt diabetic nephropathy. Kidney Int. 2006; 70:2100-2108.

27. Maxhimer JB, Somenek M, Rao G, Pesce CE, Baldwin D Jr, Gattuso P, Schwartz MM, Lewis EJ, Prinz RA, Xu $X$. Heparanase-1 gene expression and regulation by high glucose in renal epithelial cells: a potential role in the pathogenesis of proteinuria in diabetic patients. Diabetes. 2005; 54:2172-2178.

28. Garsen M, Benner M, Dijkman H, van Kuppevelt TH, Li JP, Rabelink TJ, Vlodavsky I, Berden JH, Rops AL, Elkin M, van der Vlag J. Heparanase is essential for the development of acute experimental glomerulonephritis. Am J Pathol. 2016; 186:805-15.

29. Shafat I, Agbaria A, Boaz M, Schwartz D, Baruch R, 
Nakash R, Ilan N, Vlodavsky I, Weinstein T. Elevated urine heparanase levels are associated with proteinuria and decreased renal allograft function. PloS one. 2012; 7:e44076.

30. Shafat I, Ilan N, Zoabi S, Vlodavsky I, Nakhoul F. Heparanase levels are elevated in the urine and plasma of type 2 diabetes patients and associate with blood glucose levels. PloS one. 2011; 6:e17312.

31. Rops AL, van den Hoven MJ, Veldman BA, Salemink S, Vervoort G, Elving LD, Aten J, Wetzels JF, van der Vlag J, Berden JH. Urinary heparanase activity in patients with Type 1 and Type 2 diabetes. Nephrol Dial Transplant. 2012; 27:2853-2861.

32. Levidiotis V, Freeman C, Punler M, Martinello P, Creese B, Ferro V, van der Vlag J, Berden JH, Parish CR, Power DA. A synthetic heparanase inhibitor reduces proteinuria in passive Heymann nephritis. J Am Soc Nephrol. 2004; 15:2882-2892.

33. Gil N, Goldberg R, Neuman T, Garsen M, Zcharia E, Rubinstein AM, van Kuppevelt T, Meirovitz A, Pisano C, Li JP, van der Vlag J, Vlodavsky I, Elkin M. Heparanase is essential for the development of diabetic nephropathy in mice. Diabetes. 2012; 61:208-216.

34. Rabelink TJ, van den Berg BM, Garsen M, Wang G, Elkin M, van der Vlag J. Heparanase: roles in cell survival, extracellular matrix remodelling and the development of kidney disease. Nat Rev Nephrol. 2017; 13:201-212.

35. Masola V, Zaza G, Gambaro G, Onisto M, Bellin G, Vischini G, Khamaysi I, Hassan A, Hamoud S, Nativ O, S NH, Lupo A, Vlodavsky I, Abassi Z. Heparanase: A Potential New Factor Involved in the Renal Epithelial Mesenchymal Transition (EMT) Induced by Ischemia/ Reperfusion (I/R) Injury. PloS one. 2016; 11:e0160074.

36. Lygizos MI, Yang Y, Altmann CJ, Okamura K, Hernando AA, Perez MJ, Smith LP, Koyanagi DE, Gandjeva A, Bhargava R, Tuder RM, Faubel S, Schmidt EP. Heparanase mediates renal dysfunction during early sepsis in mice. Physiol Rep. 2013; 1:e00153.

37. Rivara S, Milazzo FM, Giannini G. Heparanase: a rainbow pharmacological target associated to multiple pathologies including rare diseases. Future Med Chem. 2016; 8:647680 .

38. Dredge K, Hammond E, Handley P, Gonda TJ, Smith MT, Vincent C, Brandt R, Ferro V, Bytheway I. PG545, a dual heparanase and angiogenesis inhibitor, induces potent antitumour and anti-metastatic efficacy in preclinical models. Br J Cancer. 2011; 104:635-642.

39. Hammond E, Handley P, Dredge K, Bytheway I. Mechanisms of heparanase inhibition by the heparan sulfate mimetic PG545 and three structural analogues. FEBS Open Bio. 2013; 3:346-351.

40. Zcharia E, Metzger S, Chajek-ShaulL T, Aingorn H, Elikn M, Friedmann Y, Weinstein T, Jin-Ping L, Lindahl U, Vlodavsky I. Transgenic expression of mammalian heparanase uncovers physiological functions of heparan sulfate in tissue morphogenesis, vascularization, and feeding behavior. FASEB J. 2004; 18:252-263.

41. Abboud-Jarrous G, Atzmon R, Peretz T, Palermo C, Gadea $\mathrm{BB}$, Joyce JA, Vlodavsky I. Cathepsin L is responsible for processing and activation of proheparanase through multiple cleavages of a linker segment. J Biol Chem. 2008; 283:18167-18176.

42. Gonzalez DM, Medici D. Signaling mechanisms of the epithelial-mesenchymal transition. Sci Signal. 2014; 7:re8.

43. Zcharia E, Jia J, Zhang X, Baraz L, Lindahl U, Peretz T, Vlodavsky I, Li JP. Newly generated heparanase knockout mice unravel co-regulation of heparanase and matrix metalloproteinases. PloS one. 2009; 4:e5181.

44. Celie JW, Katta KK, Adepu S, Melenhorst WB, Reijmers RM, Slot EM, Beelen RH, Spaargaren M, Ploeg RJ, Navis G, van der Heide JJ, van Dijk MC, van Goor H, et al. Tubular epithelial syndecan-1 maintains renal function in murine ischemia/reperfusion and human transplantation. Kidney Int. 2012; 81:651-661.

45. Celie JW, Rutjes NW, Keuning ED, Soininen R, Heljasvaara R, Pihlajaniemi T, Drager AM, Zweegman S, Kessler FL, Beelen RH, Florquin S, Aten J, van den Born J. Subendothelial heparan sulfate proteoglycans become major L-selectin and monocyte chemoattractant protein-1 ligands upon renal ischemia/reperfusion. Am J Pathol. 2007; 170:1865-1878.

46. Blich M, Golan A, Arvatz G, Sebbag A, Shafat I, Sabo E, Cohen-Kaplan V, Petcherski S, Avniel-Polak S, Eitan A, Hammerman H, Aronson D, Axelman E, et al. Macrophage activation by heparanase is mediated by TLR-2 and TLR4 and associates with plaque progression. Arteriosclerosis Thromb \& Vascular Biol. 2013; 33:e56-65.

47. Masola V, Zaza G, Onisto M, Lupo A, Gambaro G. Impact of heparanase on renal fibrosis. J Transl Med. 2015; 13:181.

48. Masola V, Zaza G, Secchi MF, Gambaro G, Lupo A, Onisto $M$. Heparanase is a key player in renal fibrosis by regulating TGF-beta expression and activity. Biochim Biophys Acta. 2014; 1843:2122-2128.

49. Derynck R, Muthusamy BP, Saeteurn KY. Signaling pathway cooperation in TGF-beta-induced epithelialmesenchymal transition. Curr Opin Cell Biol. 2014; 31:5666.

50. Dhaun N, Webb DJ. The road from AKI to CKD: the role of endothelin. Kidney Int. 2013; 84:637-638.

51. Ong AC, von Websky K, Hocher B. Endothelin and tubulointerstitial renal disease. Sem Nephrol. 2015; 35:197207.

52. Hammond E, Brandt R, Dredge K. PG545, a heparan sulfate mimetic, reduces heparanase expression in vivo, blocks spontaneous metastases and enhances overall survival in the 4T1 breast carcinoma model. PLoS One. 2012; 7 :e52175.

53. de Mestre AM, Rao S, Hornby JR, Soe-Htwe T, Khachigian LM, Hulett MD. Early growth response gene 1 (EGR1) 
regulates heparanase gene transcription in tumor cells. J Biol Chem. 2005; 280: 35136-35147

54. Khachigian LM, Collins T. Inducible expression of Egr-1dependent genes. A paradigm of transcriptional activation in vascular endothelium. Circ Res. 1997; 81:457-461.

55. Gutter-Kapon L, Alishekevitz D, Shaked Y, Li JP, Aronheim A, Ilan N, Vlodavsky I. Heparanase is required for activation and function of macrophages. Proc Nat Acad Sci USA. 2016; 113:E7808-E7817.

56. Barton M, Yanagisawa M. Endothelin: 20 years from discovery to therapy. Can J Physiol Pharmacol. 2008; $86: 485-498$

57. Clozel M, Salloukh H. Role of endothelin in fibrosis and anti-fibrotic potential of bosentan. Ann Med. 2005; 37:2-12.

58. Neuhofer W, Pittrow D. Role of endothelin and endothelin receptor antagonists in renal disease. Eur J Clin Invest. 2006; 36 Suppl 3:78-88.

59. Fukui M, Nakamura T, Ebihara I, Osada S, Tomino Y, Masaki T, Goto K, Furuichi Y, Koide H. Gene expression for endothelins and their receptors in glomeruli of diabetic rats. J Lab Clin Med. 1993; 122:149-156.

60. Garsen M, Lenoir O, Rops AL, Dijkman HB, Willemsen B, van Kuppevelt TH, Rabelink TJ, Berden JH, Tharaux PL, van der Vlag J. Endothelin-1 induces proteinuria by heparanase-mediated disruption of the glomerular glycocalyx. J Am Soc Nephrol. 2016; 27:3545-3551.
61. Li JP, Galvis ML, Gong F, Zhang X, Zcharia E, Metzger S, Vlodavsky I, Kisilevsky R, Lindahl U. In vivo fragmentation of heparan sulfate by heparanase overexpression renders mice resistant to amyloid protein A amyloidosis. Pro Nat Acad Sci USA. 2005;102:6473-6477.

62. Mishra J, Ma Q, Prada A, Mitsnefes M, Zahedi K, Yang J, Barasch J, Devarajan P. Identification of neutrophil gelatinase-associated lipocalin as a novel early urinary biomarker for ischemic renal injury. J Am Soc Nephrol. 2003; 14:2534-2543.

63. Heyman SN, Rosenberger C, Rosen S. Acute kidney injury: lessons from experimental models. Contrib Nephrol. 2011;169:286-296.

64. Vlodavsky I. (1999). Preparation of extracellular matrices produced by cultured corneal endothelial and PF-HR9 endodermal cells. In: J. S. Bonifacino MD, J. B. Hartford, J. Lippincott-Schwartz and K. M. Yamada., ed. Protocols in Cell Biology. (New York: John Wiley \& Sons), pp. 10.14.11-10.14.14.61. 